\title{
Photocatalytic Decomposition of Methyl Red Dye by Using Nanosized Zinc Oxide Deposited on Glass Beads in Various pH and Various Atmosphere
}

\author{
H. R. Ebrahimi and M. Modrek \\ Department of Chemistry, Majlesi Branch, Islamic Azad University, Isfahan, Iran \\ Correspondence should be addressed to H. R. Ebrahimi; hebrahimi2010@gmail.com
}

Received 17 May 2013; Accepted 29 May 2013

Academic Editor: Hassan Karimi-Maleh

Copyright (C) 2013 H. R. Ebrahimi and M. Modrek. This is an open access article distributed under the Creative Commons Attribution License, which permits unrestricted use, distribution, and reproduction in any medium, provided the original work is properly cited.

\begin{abstract}
Photocatalytic decomposition of methyl red (MR) as a pollutant in wastewater samples is investigated in this study. This photodegradation was investigated in water in neutral, alkaline, and acidic media under external UV light irradiation by zinc oxide nanosized catalysts on granule glass. The effect of four atmosphere types including air, nitrogen, oxygen, and argon was investigated. Finally, it was found that photodecomposition using nanosized $\mathrm{ZnO}$ layered on glass is a new alternative route for efficient wastewater treatment. The results showed that the titled dye is degraded by various rate under different atmosphere and $\mathrm{pH}$.
\end{abstract}

\section{Introduction}

Nanotechnologies represent new and enabling platforms that promise to provide a broad range of novel uses and improved technologies for electrochemical, pharmaceutical, environmental, biological, and other scientific applications [1-5]. One of the reasons behind the intense interest is that nanotechnology permits the controlled synthesis of materials where at least one dimension of the structure is less than $100 \mathrm{~nm}$. Newly, nanostructured materials have also been incorporated into sensor preparation for biological and pharmaceutical analyses [5-13]. Nanomaterials exhibit many advantages such as a large ratio of surface area to volume and high activity, and they have become one of the most promising materials [14-20]. In between, Zinc oxide ( $\mathrm{ZnO})$ is an important multifunctional material with applications such as varistors, gas sensors, SAW devices, transparent electrodes, and catalysts. The various applications of $\mathrm{ZnO}$ are due to its specific chemical, surface, and microstructural properties of [21-24].

With the increasing revolution in science and technology, there was a greater demand for newer chemicals which could be used in various industrial activities [25]. Organic dyes are one of the such many new chemicals which could be used in many industrial processes including fabric, woven, leather, textile, pulp and paper, tanneries, cosmetic, pharmaceuticals, and food processings [26]. Owing to the potential toxicity of the dyes and their visibility in surface waters, removal and degradation of them have attracted considerable attention worldwide. A wide range of approaches have been developed, amongst which is the heterogeneous photocatalysis involving zinc oxide $(\mathrm{ZnO})$ that emerges as a promising new route for water purification process. Photocatalytic decolorization by semiconductors is a new, effective, and rapid technique for the removal of pollutants from water [27].

Dyes and their intermediates can undergo reductive processes and result in the formation of potentially carcinogenic or mutagenic compounds and detrimental impact towards the survival of microorganisms, aquatic life, and environmental matrix (water and soil) [28]. The ingestion of such contaminated water in the human body may also be susceptible to a broad spectrum of immune-suppression, respiratory, central nervous, neurobehavioral disorders presage as allergy, tissue necrosis, eye (or skin) infections and irritation, and even lung edema [29]. 
<smiles>CN(C)c1ccc(/N=N/c2ccccc2C(=O)O)cc1</smiles>

FIGURE 1: Schematic structure of methyl red.

Physical and biological treatments have been successfully applied until now, but these methods have their own drawbacks. The aerobic treatment process is associated with the formation and disposal of large amounts of biological sludge, while wastewater treated by the anaerobic treatment method does not lower down the pollutant contents to a satisfactory level. Activated charcoal adsorption and air-stripping methods are nondestructive, since they simply transfer the pollutants from water to another phase. They transfer it either to the atmosphere, which causes air pollution, or to a solid which is often disposed off in landfills or must be needed to regularly regenerate the adsorbent materials [30]. According to the above points, attention to wastewaters analysis increases in scientific researches [31-39].

As part of our aim is to produce zinc oxide thin film on granule glass by sol-gel coating method, in this paper, a commercial granule glass was successfully used as substrate to prepare nanosized zinc oxide thin film. The zinc oxide thin films have been employed in photocatalytic decolorization of $\mathrm{MR}$ in aqueous solutions. The schematic structure of methyl red is presented in Figure 1.

\section{Experimental}

2.1. General. All of the chemicals were analytical grade reagents without further purification and were purchased from Merck Company. The coating substrate (granule glass) was preheated at $275^{\circ} \mathrm{C}$ for $10 \mathrm{~min}$ in air after each coating. The sol-gel coating was made usually a day after the sol solution was prepared.

2.2. Film Deposition. Nanosized zinc oxide thin film was supported on glass beads (diameter of $3 \mathrm{~mm}$ ) by the following method. Glass beads were pretreated with dilute hydrofluoric acid $(5 \% \mathrm{v} / \mathrm{v})$ for $24 \mathrm{~h}$ and washed thoroughly with distilled water, making a rough surface for better contact of zinc oxide thin film on it. Zinc oxide binary sol was added to the glass beads placed in a funnel, and the excess of it was removed. They were subsequently placed in the furnace preheated at $275^{\circ} \mathrm{C}$ for $10 \mathrm{~min}$, and then postheated at $450^{\circ} \mathrm{C}$ for 1 hour. The deposition was repeated for 5 times to obtain films with different thickness [39]. Figure 2 shows SEM image of $\mathrm{ZnO}$ nanoparticle.

2.3. Photocatalytic Measurement. The photocatalytic decolorization experiments were carried out in a simple oxidation reactor, placed in a $25^{\circ} \mathrm{C}$ water bath; $5 \mathrm{~g}$ of granule glass

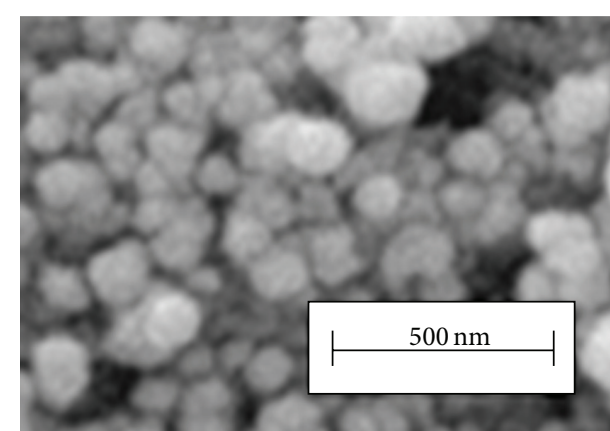

FIGURE 2: SEM image of $\mathrm{ZnO}$ nanoparticles.

with 5 layers was placed in $25 \mathrm{~mL} 25 \mathrm{ppm}$ dyes solution and was irradiated with four $8 \mathrm{~W}$ lamps (Philips; $365 \mathrm{~nm}$ ) placed $5 \mathrm{~cm}$ above the solutions. For $\mathrm{pH}$ adjustment, $0.01 \mathrm{M}$ $\mathrm{NaOH}$ and $\mathrm{HCl}$ solution was used to reach the desired $\mathrm{pH}$. Concentration was measured by spectrophotometer (Perkin Elmer, Lambda 25). In all experiments, $25 \mathrm{~mL}$ of $25 \mathrm{ppm}$ dyes solution was used with stirring during the irradiation.

\section{Results and Discussion}

3.1. Characterization Techniques for Thin Films. The structure and crystalline size were determined by XRD diffraction (Bruker D8 advanced X-ray diffractometer: $\mathrm{Cu} \mathrm{K} \alpha$ radiation). $\mathrm{X}$-ray diffraction shows zinc oxide structure with $c$-axis orientation (002) [40]. The surface of the films was observed by scanning electron microscopy (SEM) with a Philips XL30 [40].

3.2. Photocatalytic Activity. As shown in Figure 3(a), in neutral media, the dye is decolorized in oxygen and nitrogen better than air and argon. In Figure 3(b), in alkaline media, the dye is decolorized in nitrogen and air better than oxygen and argon. And finally in Figure 3(c), in acidic media, the dye is decolorized in argon and air better than oxygen and nitrogen.

For evaluating the photodegradation rate under the above conditions, the kinetic investigation was performed based on the concentration-time data in Figure 4. Generally, photodegradation of dyes obeyed first-order reactions if the plots of $\ln \left(C_{0} / C_{t}\right)$ versus time are straightforward lines. For this mean for the three above $\mathrm{pHs}$, the plots of $\ln \left(C_{0} / C_{t}\right)$ versus time were sketched and have been illustrated in Figure 4 . The behaviors of plots at all conditions were found linear after the notable initial decrease (after $10 \mathrm{~min}$ ) that may be due to adsorption of dye on catalyst surface.

The rate constants derived for neutral $\mathrm{pH}$ (Figure 4(a)) are $0.116,0.099,0.075$, and $0.068 \mathrm{mg} / \mathrm{L} \cdot \mathrm{min}$ for oxygen, nitrogen, air, and argon respectively. These values suggest more degradation in oxygen and nitrogen. The rate constants evaluated for alkaline media (Figure 4(b)) were found to be $0.081,0.069,0.053$, and $0.034 \mathrm{mg} / \mathrm{L} \cdot \mathrm{min}$ for nitrogen, air, oxygen, and argon. That again indicates more decolorization for atmospheres of nitrogen, and air, respectively. Finally, the rate constant values of acidic media (Figure 4(c)) are 


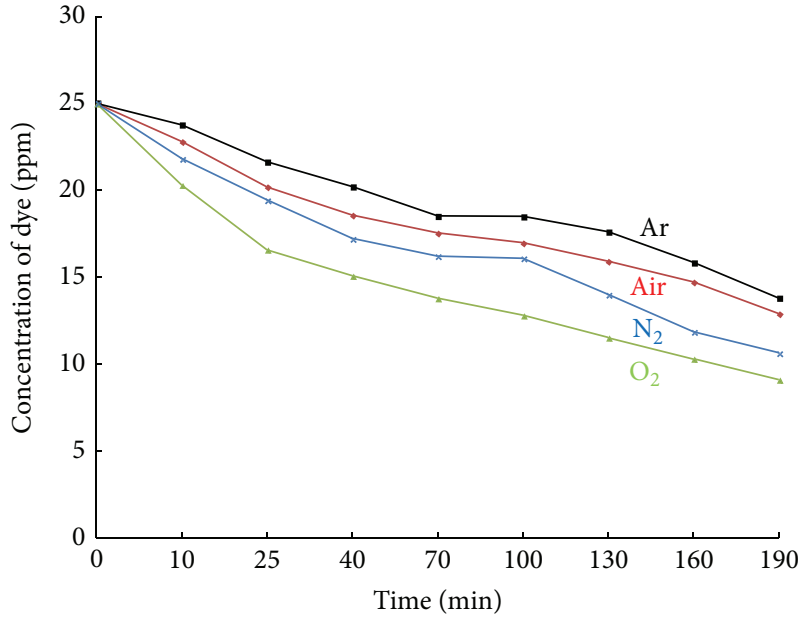

(a)

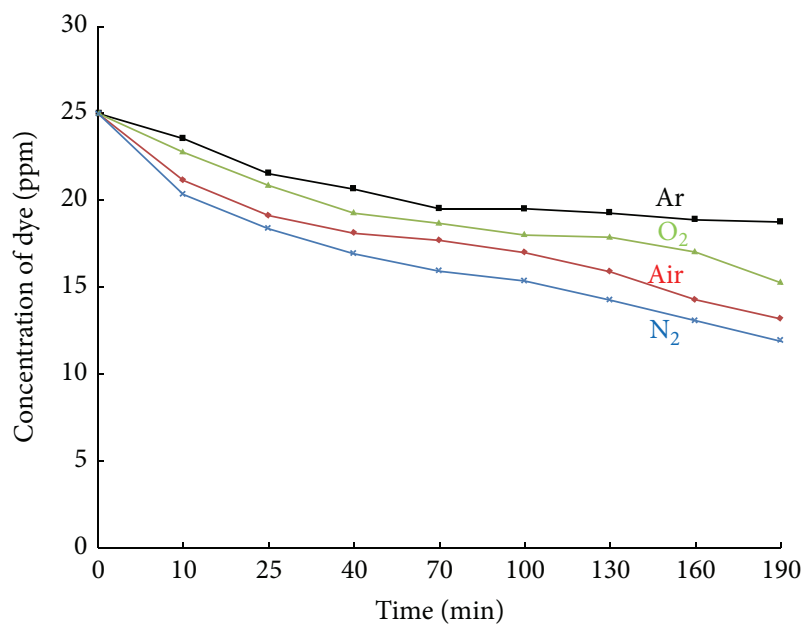

(b)

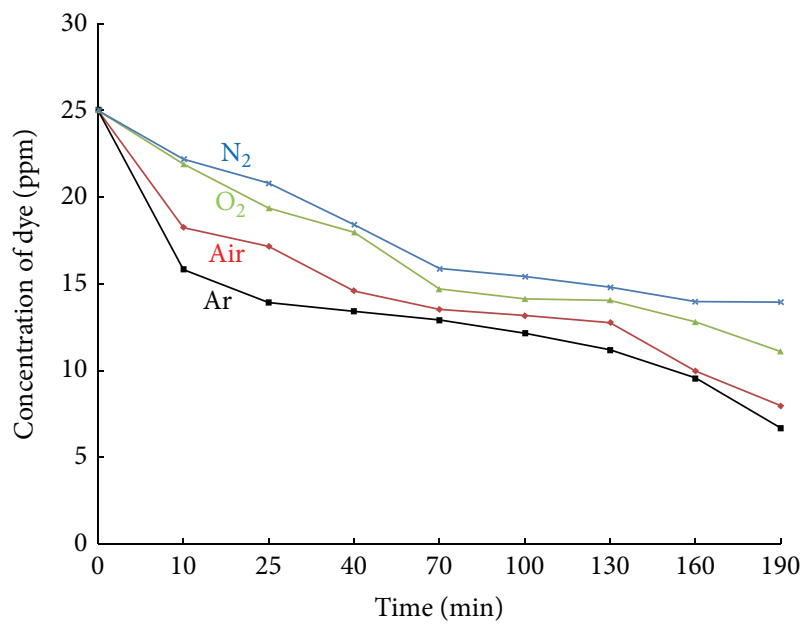

(c)

FIGURE 3: Residual concentration of MR (25 ppm) in deionized water after photocatalytic decolorization under UV irradiation in neutral $(\mathrm{pH}=7)$ medium $(\mathrm{a})$, alkaline $(\mathrm{pH}=10)$ medium $(\mathrm{b})$, and acidic $(\mathrm{pH}=5)$ medium $(\mathrm{c})$ under various atmosphere.

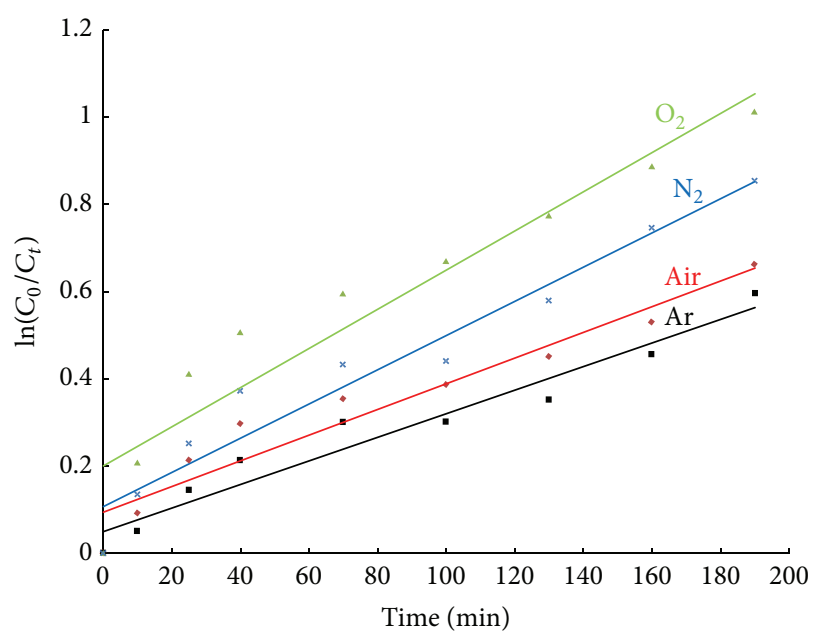

(a)

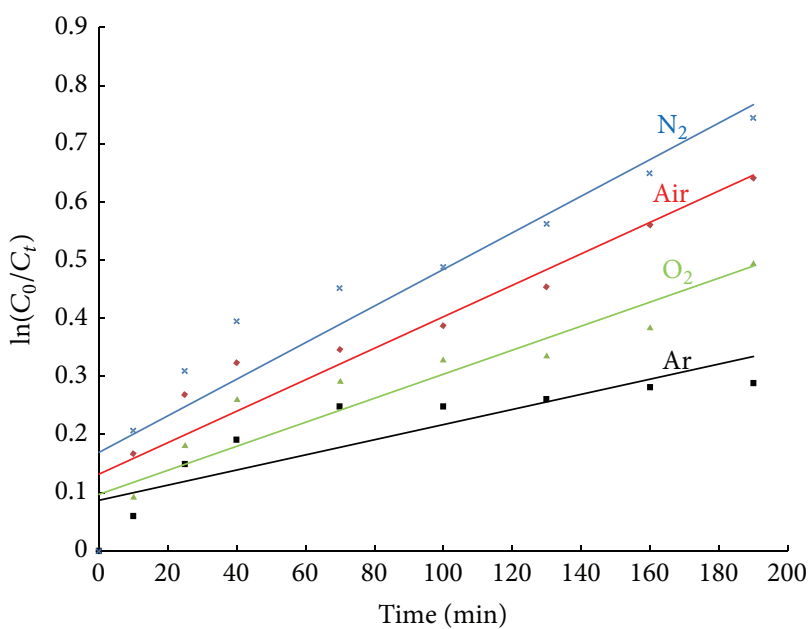

(b)

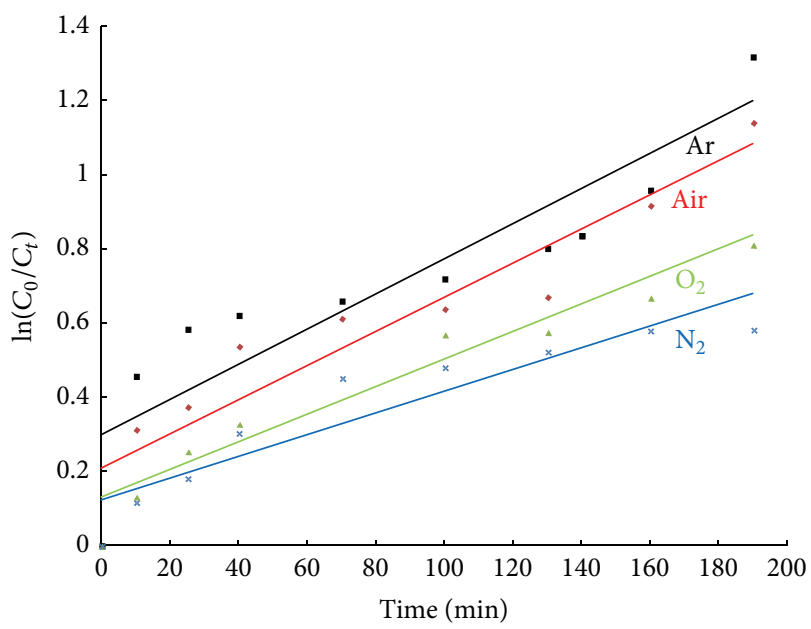

(c)

FIGURE $4: \ln \left(C_{0} / C_{t}\right)$ versus time ( $\left.\mathrm{min}\right)$ for photocatalytic decolorization under UV irradiation in neutral $(\mathrm{pH}=7)$ medium (a), alkaline $(\mathrm{pH}=10)$ medium $(\mathrm{b})$, and acidic $(\mathrm{pH}=5)$ medium $(\mathrm{c})$ under various atmosphere. 
obtained as $0.121,0.117,0.095$, and $0.076 \mathrm{mg} / \mathrm{L} \cdot \mathrm{min}$ for argon, air, oxygen, and nitrogen, respectively. which indicate more decolorization for atmospheres of argon and air.

\section{Conclusion}

In this work, we reported photocatalytic activity of nanosized zinc oxide thin film at various atmospheres: air, nitrogen, oxygen, and argon, and in different media. The titled dye was decolorized efficiently by use of this photocatalytic system. Among the considered atmospheres, orders of kinetics were found to be pseudo first order at nitrogen and oxygen. Kinetics of decolorization was investigated and was found to be pseudo-first order in various atmospheres. According to our experiments in neutral, alkaline and acidic media, oxygen, nitrogen, and argon, respectively, have the best efficiency for decolorization. Easy preparation, handling, and separation of photocatalyst from solution are some advantages of this system. Improvement of photocatalytic activity of this system by doping of some metal on catalyst surface is under investigation in our library.

\section{References}

[1] A. A. Ensafi and H. Karimi-Maleh, "Modified multiwall carbon nanotubes paste electrode as a sensor for simultaneous determination of 6-thioguanine and folic acid using ferrocenedicarboxylic acid as a mediator," Journal of Electroanalytical Chemistry, vol. 640, no. 1-2, pp. 75-83, 2010.

[2] J. B. Raoof, R. Ojani, and H. Karimi-Maleh, "Electrocatalytic oxidation of thiosulfate at 2,7-bis(ferrocenylethyl)-fluoren-9one-modified carbon paste electrode (2,7-BFEFMCPE): application to the catalytic determination of thiosulfate in real sample," Chinese Chemical Letters, vol. 21, no. 12, pp. 1462-1466, 2010.

[3] A. A. Ensafi, H. Karimi-Maleh, S. Mallakpour, and B. Rezaei, "Highly sensitive voltammetric sensor based on catecholderivative-multiwall carbon nanotubes for the catalytic determination of captopril in patient human urine samples," Colloids and Surfaces B, vol. 87, no. 2, pp. 480-488, 2011.

[4] A. Mokhtari, H. Karimi-Maleh, A. A. Ensafi, and H. Beitollahi, "Application of modified multiwall carbon nanotubes paste electrode for simultaneous voltammetric determination of morphine and diclofenac in biological and pharmaceutical samples," Sensors and Actuators B, vol. 169, pp. 96-105, 2012.

[5] T. Tavana, M. A. Khalilzadeh, H. Karimi-Maleh, A. A. Ensafi, H. Beitollahi, and D. Zareyee, "Sensitive voltammetric determination of epinephrine in the presence of acetaminophen at a novel ionic liquid modified carbon nanotubes paste electrode," Journal of Molecular Liquids, vol. 168, pp. 69-74, 2012.

[6] S. Salmanpour, T. Tavana, A. Pahlavan et al., "Voltammetric determination of norepinephrine in the presence of acetaminophen using a novel ionic liquid/multiwall carbon nanotubes paste electrode," Materials Science and Engineering C, vol. 32, pp. 1912-1918, 2012.

[7] H. Beitollah, M. Goodarzian, M. A. Khalilzadeh, H. KarimiMaleh, M. Hassanzadeh, and M. Tajbakhsh, "Electrochemical behaviors and determination of carbidopa on carbon nanotubes ionic liquid paste electrode," Journal of Molecular Liquids, vol. 173, pp. 137-143, 2012.
[8] H. Karimi-Maleh, P. Biparva, and M. Hatami, "A novel modified carbon paste electrode based on $\mathrm{NiO} / \mathrm{CNT}$ nanocomposite and (9, 10-dihydro-9, 10-ethanoanthracene-11, 12-dicarboximido)4-ethylbenzene-1, 2-diol as a mediator for simultaneous determination of cysteamine, nicotin amide adenine dinucleotide and folic acid," Biosensors and Bioelectronics, vol. 48, pp. 270275, 2013.

[9] M. Keyvanfard, R. Shakeri, H. Karimi-Maleh, and K. Alizad, "Highly selective and sensitive voltammetric sensor based on modified multiwall carbon nanotube paste electrode for simultaneous determination of ascorbic acid, acetaminophen and tryptophan," Materials Science and Engineering C, vol. 33, pp. 811-816, 2013.

[10] M. R. Shahmiri, A. Bahari, H. Karimi-Maleh, R. Hosseinzadeh, and N. Mirnia, "Ethynylferrocene-NiO/MWCNT nanocomposite modified carbon paste electrode as a novel voltammetric sensor for simultaneous determination of glutathione and acetaminophen," Sensors and Actuators B, vol. 177, pp. 70-77, 2013.

[11] M. Ansari, S. Kazemi, M. A. Khalilzadeh, H. Karimi-Maleh, and M. B. P. Zanousi, "Sensitive and stable voltammetric measurements of norepinephrine at ionic liquid-carbon nanotubes paste electrodes," International Journal of Electrochemical Science, vol. 8, pp. 1938-1948, 2013.

[12] M. Baghayeri, M. Namadchian, H. Karimi-Maleh, and H. Beitollahi, "Determination of nifedipine using nanostructured electrochemical sensor based on simple synthesis of $\mathrm{Ag}$ nanoparticles at the surface of glassy carbon electrode: application to the analysis of some real samples," Journal of Electroanalytical Chemistry, vol. 697, pp. 53-59, 2013.

[13] M. Fouladgar, H. Karimi-Maleh, and R. Hosseinzadeh, "Novel nanostructured electrochemical sensor for voltammetric determination of $\mathrm{N}$-acetylcysteine in the presence of high concentrations of tryptophan," Ionics, vol. 19, pp. 665-672, 2013.

[14] M. Fouladgar and H. Karimi-Maleh, "Ionic liquid/multiwall carbon nanotubes paste electrode for square wave voltammetric determination of methyldopa," Ionics, 2013.

[15] A. A. Ensafi, H. Karimi-Maleh, and S. Mallakpour, "A new strategy for the selective determination of glutathione in the presence of nicotinamide adenine dinucleotide (NADH) using a novel modified carbon nanotube paste electrode," Colloids and Surfaces B, vol. 104, pp. 186-193, 2013.

[16] A. A. Ensafi, M. Izadi, and H. Karimi-Maleh, "Sensitive voltammetric determination of diclofenac using room-temperature ionic liquid-modified carbon nanotubes paste electrode," Ionics, vol. 19, pp. 137-144, 2013.

[17] M. Keyvanfard, S. Sami, H. Karimi-Maleh, and K. Alizad, "Electrocatalytic determination of cysteamine using multiwall carbon nanotube paste electrode in the presence of 3, 4dihydroxycinnamic acid as a homogeneous mediator," Journal of the Brazilian Chemical Society, vol. 24, pp. 32-39, 2013.

[18] M. Keyvanfard, V. Khosravi, H. Karimi-Maleh, K. Alizad, and B. Rezaei, "Voltammetric determination of 6-mercaptopurine using a multiwall carbon nanotubes paste electrode in the presence of isoprenaline as a mediator," Journal of Molecular Liquids, vol. 177, pp. 182-189, 2013.

[19] A. A. Ensafi, H. Bahrami, B. Rezaei, and H. Karimi-Maleh, "Application of ionic liquid- $\mathrm{TiO}_{2}$ nanoparticle modified carbon paste electrode for the voltammetric determination of benserazide in biological samples," Materials Science and Engineering C, vol. 33, pp. 831-835, 2013. 
[20] S. Gheibi, H. Karimi-Maleh, M. A. Khalilzadeh, and H. Bagheri, "A new voltammetric sensor for electrocatalytic determination of vitamin $\mathrm{C}$ in fruit juices and fresh vegetable juice using modified multi-wall carbon nanotubes paste electrode," Journal of Food Science and Technology.

[21] R. Sadeghi, H. Karimi-Maleh, A. Bahari, and M. Taghavi, "A novel biosensor based on $\mathrm{ZnO}$ nanoparticle/1, 3-dipropylimidazolium bromide ionic liquid-modified carbon paste electrode for square-wave voltammetric determination of epinephrine," Physics and Chemistry of Liquids, 2013, http://dx.doi .org/10.1080/00319104.2013.782547.

[22] S. T. Shishiyanu, T. S. Shishiyanu, and O. I. Lupan, "Sensing characteristics of tin-doped $\mathrm{ZnO}$ thin films as $\mathrm{NO}_{2}$ gas sensor," Sensors and Actuators B, vol. 107, no. 1, pp. 379-386, 2005.

[23] E. Afsharmanesh, H. Karimi-Maleh, A. Pahlavan, and J. Vahedi, "Electrochemical behavior of morphine at $\mathrm{ZnO} / \mathrm{CNT}$ nanocomposite room temperature ionic liquid modified carbon paste electrode and its determination in real samples," Journal of Molecular Liquids, vol. 181, pp. 8-13, 2013.

[24] M. Bijad, H. Karimi-Maleh, and M. A. Khalilzadeh, "Application of $\mathrm{ZnO} / \mathrm{CNTs}$ nanocomposite ionic liquid paste electrode as a sensitive voltammetric sensor for determination of ascorbic acid in food samples," Food Analytical Methods.

[25] V. K. Gupta and Suhas, "Application of low-cost adsorbents for dye removal-a review," Journal of Environmental Management, vol. 90, no. 8, pp. 2313-2342, 2009.

[26] R. Moradi, S. A. Sebt, H. Karimi-Maleh et al., "Synthesis and application of FePt/CNTs nanocomposite as a sensor and novel amide ligand as a mediator for simultaneous determination of glutathione, nicotinamide adenine dinucleotide and tryptophan," Physical Chemistry Chemical Physics, vol. 15, pp. 58885897, 2013.

[27] K. Vinodgopal, I. Bedja, S. Hotchandani, and P. V. Kamat, "A photocatalytic approach for the reductive decolorization of textile azo dyes in colloidal semiconductor suspensions," Langmuir, vol. 10, no. 6, pp. 1767-1771, 1994.

[28] A. R. Khataee, M. Zarei, and L. Moradkhannejhad, "Application of response surface methodology for optimization of azo dye removal by oxalate catalyzed photoelectro-Fenton process using carbon nanotube-PTFE cathode," Desalination, vol. 258, no. 1-3, pp. 112-119, 2010.

[29] K. Y. Foo and B. H. Hameed, "Decontamination of textile wastewater via $\mathrm{TiO}_{2}$ /activated carbon composite materials," Advances in Colloid and Interface Science, vol. 159, no. 2, pp. 130$143,2010$.

[30] B. H. Hameed, U. G. Akpan, and K. P. Wee, "Photocatalytic degradation of acid red 1 dye using $\mathrm{ZnO}$ catalyst in the presence and absence of silver," Desalination and Water Treatment, vol. 27, no. 1-3, pp. 204-209, 2011.

[31] D. Afzali, H. Karimi-Maleh, and M. A. Khalilzadeh, "Sensitive and selective determination of phenylhydrazine in the presence of hydrazine at a ferrocene-modified carbon nanotube paste electrode," Environmental Chemistry Letters, vol. 9, no. 3, pp. 375-381, 2011.

[32] A. A. Ensafi, M. Lotfi, and H. Karimi-Maleh, "New modifiedmultiwall carbon nanotubes paste electrode for electrocatalytic oxidation and determination of hydrazine using square wave voltammetry," Chinese Journal of Catalysis, vol. 33, no. 2-3, pp. 487-493, 2012.

[33] H. Karimi-Maleh, A. A. Ensafi, H. Beitollahi, V. Nasiri, M. A. Khalilzadeh, and P. Biparva, "Electrocatalytic determination of sulfite using a modified carbon nanotubes paste electrode: application for determination of sulfite in real samples," Ionics, vol. 18, pp. 687-694, 2012.

[34] R. Sadeghi, H. Karimi-Maleh, M. A. Khalilzadeh, H. Beitollahi, Z. Ranjbarha, and M. B. Pasha Zanousi, "A new strategy for determination of hydroxylamine and phenol in water and waste water samples using modified nanosensor," Environmental Science and Pollution Research, 2013.

[35] M. A. Khalilzadeh and H. Karimi-Maleh, "Sensitive and selective determination of phenylhydrazine in the presence of hydrazine at a ferrocene monocarboxylic acid modified carbon nanotube paste electrode," Analytical Letters, vol. 43, no. 1, pp. 186-196, 2010.

[36] J. B. Raoof, R. Ojani, and H. Karimi-Maleh, "Electrocatalytic determination of sulfite using 1-[4-(ferrocenylethynyl) phenyl]1-ethanone modified carbon paste electrode," Asian Journal of Chemistry, vol. 20, no. 1, pp. 483-494, 2008.

[37] A. A. Ensafi and H. Karimi-Maleh, "Ferrocenedicarboxylic acid modified multiwall carbon nanotubes paste electrode for voltammetric determination of sulfite," International Journal of Electrochemical Science, vol. 5, no. 3, pp. 392-406, 2010.

[38] A. A. Ensafi, H. Karimi-Maleh, and M. Keyvanfard, "A new voltammetric sensor for the determination of sulfite in water and wastewater using modified-multiwall carbon nanotubes paste electrode," International Journal of Environmental Analytical Chemistry, vol. 93, no. 6, pp. 650-660, 2013.

[39] H. Beitollahi, S. Tajik, H. Karimi-Maleh, and R. Hosseinzadeh, "Application of a 1-benzyl-4-ferrocenyl-1H-[1-3]triazole/carbon nanotube modified glassy carbon electrode for voltammetric determination of hydrazine in water samples," Applied Organometallic Chemistry, 2013.

[40] H. R. Ebrahimi, "Preparation of metal catalysts on granule glass for degradation of textile dyes as environmental contaminants," World Applied Sciences Journal, vol. 3, pp. 738-741, 2008. 

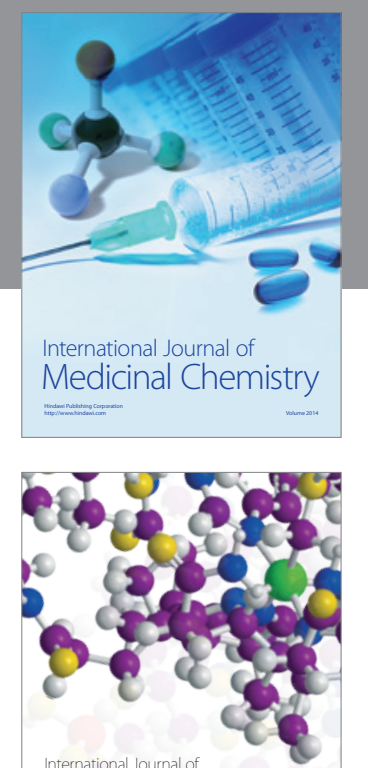

\section{Carbohydrate} Chemistry

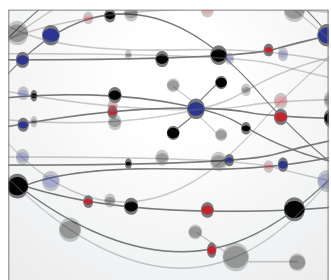

The Scientific World Journal
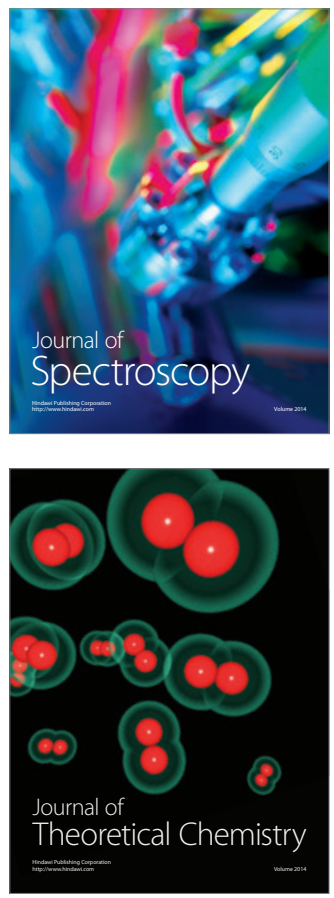
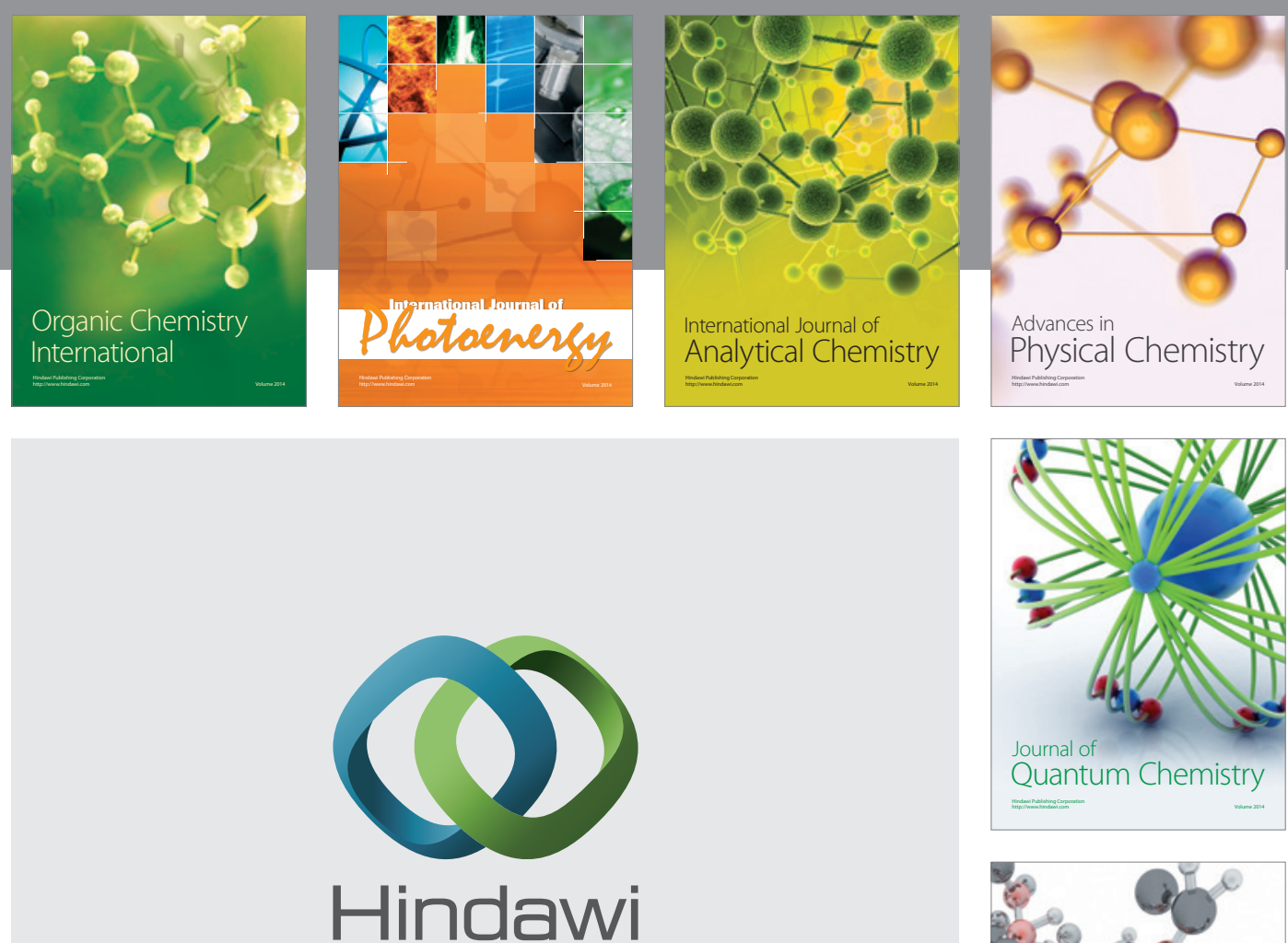

Submit your manuscripts at

http://www.hindawi.com

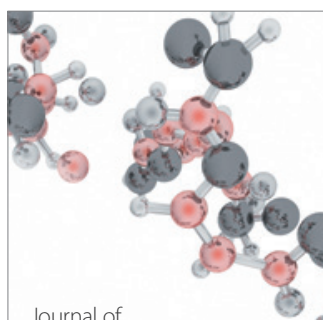

Analytical Methods

in Chemistry

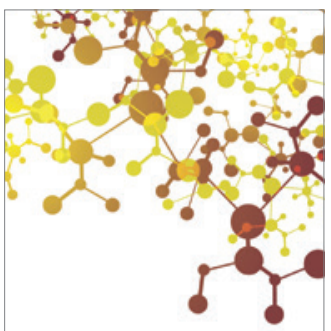

Journal of

Applied Chemistry

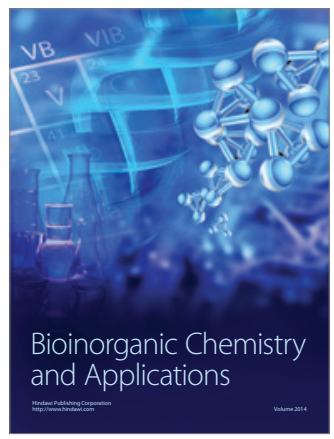

Inorganic Chemistry
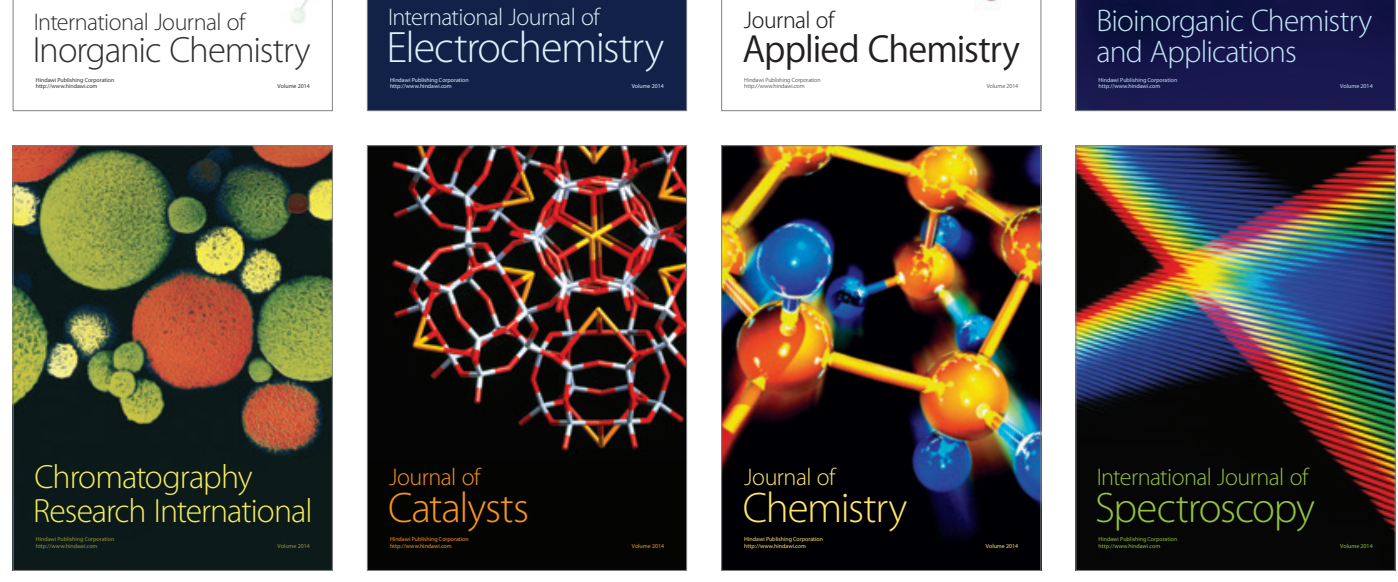